\title{
Plasma 17-hydroxyprogesterone in newborn infants with congenital adrenal hyperplasia and in infants with normal adrenal function
}

\author{
SHELIA M. ATHERDEN, A. T. EDMUNDS, and D. B. GRANT \\ From The Hospital for Sick Children, London; Northwick Park Hospital and the Clinical Research Centre, \\ Harrow, Middlesex
}

\begin{abstract}
Atherden, S. M., Edmunds, A. T., and Grant, D. B. (1974). Archives of Disease in Childhood, 49, 192. Plasma 17-hydroxyprogesterone in newborn infants with congenital adrenal hyperplasia and in infants with normal adrenal function. Plasma 17-hydroxyprogesterone (17-OHP) was estimated in 9 infants aged 6 to 12 days with congenital adrenal hyperplasia (CAH) due to 21-hydroxylase deficiency. Raised plasma 17-OHP values, ranging from 3.4 to $25 \cdot 0 \mu \mathrm{g} / 100 \mathrm{ml}$ were found. 50 infants aged 10 hours to 15 days with normal adrenal function were also studied. One infant with galactosaemia had 17-OHP levels of $1 \cdot 8$ and $2 \cdot 4 \mu \mathrm{g} / 100$ $\mathrm{ml}$, and a further 3 infants aged 15 hours to 3 days had 17-OHP levels between $1 \cdot 1$ and $2 \cdot 1 \mu \mathrm{g} / 100 \mathrm{ml}$. In the remaining infants, plasma $17-0 H P$ was less than $1.0 \mu \mathrm{g} / 100$ $\mathrm{ml}$. It therefore appears that estimation of plasma 17-OHP provides a useful method for confirming the diagnosis of $\mathrm{CAH}$ during the newborn period.
\end{abstract}

Congenital adrenal hyperplasia (CAH) is due, in the majority of cases, to a deficiency of 21-hydroxylase, the enzyme required for the hydroxylation of 17-hydroxyprogesterone (17-OHP) in the biosynthesis of cortisol. This results in a conspicuous rise of the plasma 17-OHP concentration (Strott, Yoshimi, and Lipsett, 1969).

We have described a simple method for estimating plasma 17-OHP (Barnes and Atherden, 1972), and the present paper gives results obtained with this method in infants with normal adrenal function and in newborn infants with $\mathrm{CAH}$ or suspected $\mathrm{CAH}$.

Patients.

\section{Patients and methods}

Infants with $C A H$. Specimens were obtained from 3 male and 6 female infants aged 6 to 12 days with CAH. The diagnosis was confirmed in these patients by analysis of urinary steroids. 6 had the salt-losing form of the disorder.

Infants with suspected $C A H$. Plasma samples were obtained from 9 infants aged 18 hours to 14 days in whom CAH was suspected because of persistent vomiting, abnormal external genitalia, or a family history of the

Received 21 August 1973. disorder. In all these patients, the diagnosis of $\mathrm{CAH}$ was excluded by the subsequent clinical and laboratory findings.

Infants with normal adrenal function. 49 specimens were collected from 41 infants without evidence of adrenal disease at the same time as blood was taken for investigation of conditions such as jaundice, hypoglycaemia, or suspected sepsis. 23 infants were male and 18 were female, ages ranging from 10 hours to 15 days.

Methods. Heparinized blood samples were obtained by heel prick or venepuncture between 9.00 and 12.00 hours. Plasma samples were stored frozen until used.

Details of the method used to estimate plasma 17-OHP have been published elsewhere (Barnes and Atherden, 1972).

\section{Results}

Plasma 17-OHP results for the three groups of patients are shown in the Fig.

Infants with CAH. Plasma 17-OHP levels were raised in all the infants with $\mathrm{CAH}$, ranging from 3.4 to $25.0 \mu \mathrm{g} / 100 \mathrm{ml}$.

Two samples were obtained from 3 patients. In 1 the plasma 17-OHP rose from $6.0 \mu \mathrm{g} / 100 \mathrm{ml}$ on 


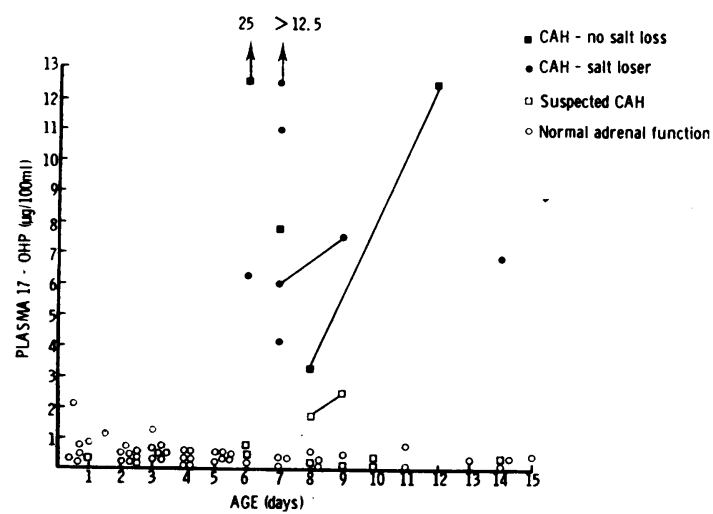

FIG.-Plasma 17-hydroxyprogesterone (17-OHP) levels in 9 infants with congenital adrenal hyperplasia (CAH), 9 infants with suspected but unconfirmed $C A H$, and 40 infants with normal adrenal function.

day 7 to $7 \cdot 5 \mu \mathrm{g}$ on day 9 , and in another from 3.4 $\mu \mathrm{g} / 100 \mathrm{ml}$ on day 8 to $12.5 \mu \mathrm{g}$ on day 12 . In one infant aged 7 days the morning 17-OHP value was greater than $12.5 \mu \mathrm{g} / 100 \mathrm{ml}$ and the midnight value was $10 \cdot 0 \mu \mathrm{g}$.

Infants with suspected CAH. Plasma 17-OHP levels of $1.8 \mu \mathrm{g} / 100 \mathrm{ml}$ (day 8 ) and 2.4 $\mu \mathrm{g} / 100 \mathrm{ml}$ (day 9) were found in 1 infant with galactosaemia who was extremely ill with persistent vomiting, dehydration, and jaundice. The urinary 11-oxygenation index (Clayton, Edwards, and Makin, 1971) was abnormally raised in this patient, but normal adrenal glands were found post mortem. The liver showed gross fatty changes.

In the remaining 8 patients plasma $17-\mathrm{OHP}$ levels were less than $1.0 \mu \mathrm{g} / 100 \mathrm{ml}$.

Infants with normal adrenal function. In 45 samples from 37 infants, plasma 17-OHP values below $1.0 \mu \mathrm{g} / 100 \mathrm{ml}$ were obtained. In one infant aged 15 hours plasma $17-\mathrm{OHP}$ was $2 \cdot 1 \mu \mathrm{g} / 100 \mathrm{ml}$ and in 2 further infants aged 2 and 3 days the levels were $1 \cdot 1 \mu \mathrm{g}$ and $1.3 \mu \mathrm{g}$, respectively.

A heavily haemolysed sample from an infant aged 6 days gave a 17-OHP value of $4 \cdot 2 \mu \mathrm{g} / 100 \mathrm{ml}$ (not shown in the Fig.). The extract from this sample was discoloured and this almost certainly accounted for the abnormal result. 17-OHP could not be detected in a further sample from this infant.

\section{Discussion}

Tests for CAH which are based on analysis of urinary steroids may give misleading results during the newborn period. In normal infants urinary 17-oxosteroid excretion is usually slightly raised during the first few days of life. Conversely, in infants with 21-hydroxylase deficiency, pregnanetriol may not be found in the urine during this period (Shackleton, Mitchell, and Farquhar, 1972). In addition, false-positive or false-negative results may be obtained for the urine 11-oxygenation index (Clayton et al., 1971).

The findings reported by Jenner, Grumbach, and Kaplan (1970) and by Franks (1972), together with the results described in this paper, indicate that estimation of plasma 17-OHP may provide a more reliable method for confirming the diagnosis of CAH during the neonatal period. Jenner et al. (1970) found a plasma $17-\mathrm{OHP}$ value of $5 \cdot 7 \mu \mathrm{g} / 100 \mathrm{ml}$ in a 4-day-old infant with CAH and Franks (1972) reported an average 17-OHP level of $44 \cdot 8 \mu \mathrm{g} / 100$ $\mathrm{ml}$ in 4 infants with $\mathrm{CAH}$ who were less than a month old. In the present study, conspicuously raised 17-OHP levels were found in 9 infants with $\mathrm{CAH}$ aged 6 to 14 days, and it therefore appears that a high proportion of infants with 21-hydroxylase deficiency have raised plasma 17-OHP levels by the end of the first week of life. As our youngest patients were 6 days old, the results do not permit any conclusions as to how soon after delivery abnormally high 17-OHP levels can be detected. It is still not known whether patients with a very mild form of CAH have raised 17-OHP levels soon after birth, but it seems unlikely that false-negative results will be common in patients with the salt-losing form of the disorder.

In older children with defective 21-hydroxylation there is a marked circadian variation in plasma 17-OHP, and relatively low values may be found in the late evening (Atherden, Barnes, and Grant, 1972). In the present study all but one of the specimens were obtained between 9.00 and 12.00 hours and we have not systematically investigated the possibility that plasma 17-OHP levels may vary at different times of the day in newborn infants. However, as the adult circadian pattern of corticotrophin secretion is probably absent in young children (Franks, 1967), it seems that the time when samples are obtained is unlikely to be important during the neonatal period. This conclusion is supported by our findings in one infant who showed a conspicuous rise of plasma 17-OHP in a sample collected at midnight.

While the method used in this study is relatively simple, it is not specific for 17-OHP and any progesterone which is present will also be extracted and estimated. As the plasma progesterone concentration in $\mathrm{CAH}$ is only about 3 to $13 \%$ of that of 17-OHP (Strott et al., 1969; Simopoulos et al. 
1971), and as progesterone shows less than half the competition for the assay binding protein when compared with 17-OHP (Barnes and Atherden, 1972), errors caused by this lack of specificity are likely to be small in patients with CAH. However, it was important to establish that the relatively high plasma progesterone levels found at birth in normal infants (Conly et al., 1968) did not invalidate results obtained during the early neonatal period. The above results indicate that the method rarely gives $17-O H P$ values above $1 \mu \mathrm{g} / 100 \mathrm{ml}$ after the first day of life in normal infants. However, the findings in an infant with galactosaemia suggest that moderately high 17-OHP values may be obtained occasionally in extremely ill infants who do not have CAH. It is of interest that the 11-oxygenation index was also raised in this case.

Many of the samples used in this study were icteric or slightly haemolysed. Though such samples are suitable for estimation of plasma 17-OHP, results obtained with heavily haemolysed specimens should be viewed with suspicion as discoloration of the plasma extract is likely to invalidate the method. High 17-OHP values obtained under these conditions should be confirmed using a further unhaemolysed sample.

We thank the paediatricians who referred patients to us with CAH or suspected CAH.
Atherden, S. M., Barnes, N. D., and Grant, D. B. (1972). Circadian variation in plasma 17-hydroxyprogesterone in patients with congenital adrenal hyperplasia. Archives of Disease in Childhood, 47, 602.

Barnes, N. D., and Atherden, S. M. (1972). Diagnosis of congenital adrenal hyperplasia by measurement of plasma 17-hydroxyprogesterone. Archives of Disease in Childhood, 47, 62.

Clayton, B. E., Edwards, R. W. H., and Makin, H. L. J. (1971). Congenital adrenal hyperplasia and other conditions associated with a raised urinary steroid 11-oxygenation index. Fournal of Endocrinology, 50, 251.

Conly, P. W., Morrison, T., Sandberg, D. H., and Cleveland, W. W. (1968). Plasma progesterone in the perinatal and neonatal period. (Abst.) Pediatric Research, 2, 308.

Franks, R. C. (1967). Diurnal variation of plasma 17-hydroxycorticosteroids in children. Fournal of Clinical Endocrinology and Metabolism, 27, 75.

Franks, R. C. (1972). Screening tests for congenital adrenal hyperplasia. fournal of Clinical Endocrinology and Metabolism, 35, 831.

Jenner, M. R., Grumbach, M. M., and Kaplan, S. L. (1970). Plasma 17-OH progesterone in maternal and umbilical cord plasma in children and in congenital adrenal hyperplasia. (Abst.) Pediatric Research, 4, 380.

Shackleton, C. H., Mitchell, F. L., and Farquhar, J. W. (1972). Difficulties in the diagnosis of the adrenogenital syndrome in infancy. Pediatrics, 49, 198.

Simopoulos, A. P., Marshall, J. R., Delea, C. S., and Bartter, F. C. (1971). Studies on the deficiency of 21-hydroxylation in patients with congenital adrenal hyperplasia. fournal of Clinical Endocrinology and Metabolism, 32, 438.

Strott, C. A., Yoshimi, T., and Lipsett, M. B. (1969). Plasma progesterone and 17-hydroxyprogesterone in normal men, and children with congenital adrenal hyperplasia. Fournal of Clinical Investigation, 48, 930.

Correspondence to Dr. D. B. Grant, Clinical Research Centre, Watford Road, Harrow, Middlesex HA1 3UJ. 